\title{
Effect of IUDs on uterine cyclic AMP in rabbits
}

\author{
D. J. Jones*, A. Sabry†t and B. J. Hodgson $\dagger$ \\ * Departments of Anesthesiology and $\dagger$ Obstetrics and Gynecology, \\ University of Texas Health Science Center, 7703 Floyd Curl Drive, \\ San Antonio, Texas 78284, U.S.A.
}

The mechanism(s) whereby an intrauterine device (IUD) prevents implantation are poorly understood (Eckstein, 1970). Sim (1974) showed that the presence of an IUD in the rat uterus was associated with an increase in cyclic AMP content and adenyl cyclase activity. Cyclic AMP has been implicated in a variety of uterine biosynthetic processes (Hechter, Yoshinaga, Halkerston \& Birchall, 1967) and in the control of spontaneous uterine contractions (Johansson \& Anderson, 1975). The present study was designed to determine the effect of a plastic and copper-bearing IUD on levels of cyclic AMP in the uteri of oestrous rabbits.

The IUDs were inserted under barbiturate anaesthesia into the uteri of 15 New Zealand White rabbits so that each horn received a plastic IUD, a plastic-copper IUD or no IUD on a random basis. The IUDs, which were portions of Copper-T IUDs (kindly donated by Ortho Pharmaceuticals, Raritan, New Jersey) and $1.8 \mathrm{~cm}$ in length, were inserted through a small incision just anterior to the cervix and were secured to the uterine wall with a suture (4-0 silk). After 1, 2 or 3 months, the uteri were removed under barbiturate anaesthesia and immediately placed in liquid nitrogen. In three animals, IUDs were removed after 2 months and uteri were excised 1 month later. Uterine tissue samples, 3 or 4 from each uterus and $20-30 \mathrm{mg}$ each, were taken from the region adjacent to the site of the IUD. Cyclic AMP was measured in neutralized, acid-extracted supernatants by the radioimmunoassay procedure of Steiner, Kipnis, Utiger \& Parker (1969). The cyclic AMP antibody, radioactive cyclic AMP ligand and cyclic AMP standards were purchased from Schwarz Mann (Orangeburg, New York). The recovery of cyclic AMP from extracted tissue samples was 91-94\% as determined by recovery of the $\left[{ }^{3} \mathrm{H}\right]$ cyclic AMP standard. Data were tested for significance using Student's one-tailed $t$ test.

Levels of cyclic AMP in control (no IUD in either horn) and IUD-containing uteri are shown in Table 1. Cyclic AMP was significantly $(P<0.04)$ lower in the uteri containing plastic or plasticcopper IUDs by 1 month and remained depressed for up to 3 months. Levels returned to control values in animals in which the plastic IUD was removed at 2 months, but remained depressed after removal of the plastic-copper IUDs.

Table 1. The effects (mean \pm S.E.M.) of plastic and copper-plastic IUDs on the concentrations of cyclic AMP (pmol/mg tissue wet weight) in the uteri of rabbits (no. of samples in parentheses)

\begin{tabular}{lccc}
\hline $\begin{array}{c}\text { Time after IUD } \\
\text { insertion }\end{array}$ & Plastic IUD & Copper IUD & No IUD \\
\hline - & - & - & $0.58 \pm 0.08^{*}(10)$ \\
1 month & $0.27 \pm 0.03(12)$ & $0.38 \pm 0.05(16)$ & $0.50 \pm 0.04 \uparrow(6)$ \\
2 months & $0.38 \pm 0.04(18)$ & $0.32 \pm 0.03(20)$ & \\
3 months & $0.40 \pm 0.04(12)$ & $0.36 \pm 0.04(20)$ \\
3 months $\ddagger$ & $0.55 \pm 0.05(16)$ & $0.25 \pm 0.04(7)$ \\
& & \\
& * No IUD in either horn. \\
& $\dagger$ IUD in contralateral horn. \\
& $\ddagger$ IUD removed after 2 months.
\end{tabular}

$\ddagger$ Present address: Mabarrah_Hospital, Assiut, Egypt. 
This study indicates that the presence of an IUD is associated with decreased uterine cyclic AMP in oestrous rabbit uteri. Plastic and plastic-copper IUDs did not differ in their ability to depress cyclic AMP, although there was a difference between them in the duration of the depression. If there is a correlation between the effects of IUDs on uterine cyclic AMP and fertility, the return of cyclic AMP to normal levels with plastic IUDs in the present study explains the findings of Marston \& Chang (1969) and Bartke (1968), who showed that a thread IUD in rabbits and mice, respectively, could be removed up to $196 \mathrm{~h}$ after mating and permit normal fetal development.

The decrease in uterine cyclic AMP produced by the copper IUD is consistent with the studies of Perkins (1973) and Singh \& Dhallas (1975) in which low concentrations of copper in vitro produced a dose-dependent inhibition of adenyl cyclase. Moreover, Zipper, Medel \& Prager (1969) showed that intrauterine copper wire can prevent implantation in rabbits. Failure of implantation due to copper is caused by an alteration of the endometrial environment and not to some direct effect of copper on the zygotes (Oster \& Salgo, 1975). Therefore, since fertility in rats is established immediately after removal of the copper IUD (Dr P. Nutting, personal communication) one would expect the 'altered' endometrial environment to return to normal immediately after IUD removal. On this basis, a causeeffect relationship between decreased cyclic AMP and the antifertility effect of the copper IUD cannot be established. There is no information available concerning the delayed effects of a copper IUD on fertility in rabbits or rats and this aspect warrants further study.

Our results are in contrast to those of Sim (1974) who found an increase in cyclic AMP in rat uteri containing a nylon IUD. This may refiect a species difference in the sensitivities of adenyl cyclase and phosphodiesterase and/or a specific effect of copper on enzymes associated with generation of cyclic AMP. Decreased cyclic AMP in rabbit uteri could be associated with increased contractile activity of the uterus, because increased cyclic AMP has been associated with relaxation (Triner et al., 1971) and cupric ions at low concentrations $\left(10^{6}-10^{5} \mathrm{M}\right)$ have been shown to cause uterine contraction (Salgo \& Oster, 1973).

This work was supported by the Rockefeller Foundation and A.S. was a Rockefeller Foundation Postdoctoral Fellow in Reproductive Biology.

\section{References}

BARTKE, A. (1968) Effect of an IUD on implantation and the decidual reaction in different strains of mice. $J$. Reprod. Fert. 15, 185-190.

ECKSTEIN, P. (1970) Mechanism of action of intrauterine contraceptive devices in women and other mammals. Br. med. Bull. 26, 52-59.

Hechter, O., Yoshinaga, K., Halkerston, I.D. \& BirCHALL, K. (1967) Oestrogen-like anabolic effects of cyclic $3^{\prime}-5^{\prime}$-adenosine monophosphate and other nucleotides in isolated rats uterus. Archs Biochem. Biophys. 122, 449-454.

JoHANSSON, S. \& ANDERSON, R.G.G. (1975) Variations of cyclic nucleotide monophosphate levels during spontaneous uterine contractions. Experientia 37, $1314-1315$.

Marston, J.H. \& Chang, M.C. (1969) Contraceptive action of intrauterine devices in the rabbit. $J$. Reprod. Fert. 11, 409-418.

OSter, G. \& Salgo, M.P. (1975) The copper intrauterine device and its mode of action. New Engl.J. Med.293, $432-436$.

Perkins, J.P. (1973) Adenyl cyclase. Adv. cyclic Nucleotide Res. 3, 1-65.
SAlgo, M.P. \& Oster, G. (1973) Copper stimulation and inhibition of the rat uterus. Fert. Steril. 25, 113120.

SiM, M.K. (1974) Effects of IUD on uterine cyclic AMP and the activities of adenyl cyclase and phosphodiesterase during the oestrous cycle and early pregnancy in rats. J. Reprod. Fert. 39, 399-402.

Singh, J.N. \& Dhallas, N.S. (1975) Adenylate cyclase activation in lymphoid tissue during graft-versus-host reaction. Adv. cyclic Necleotide Res. 5, 759-770.

Steiner, A.L., KiPnis, D.M., Utiger, R. \& PARker, C. (1969) Radioimmunoassay of cyclic nucleotides. Proc, natn. Acad. Sci. U.S.A. 64, 1121-1124.

Triner, L., Nahas, G.G., Vúlllemoz, Y., Overweg, N.I.A., VeroskY, M., HaBif, D.V. \& Nagi, S.H. (1971) Cyclic AMP and smooth muscle function. Ann. N.Y. Acad. Sci. 185, 458-476.

ZipPer, J., Medel, M. \& PRAGer, R. (1969) Suppression of fertility by intrauterine copper and zinc in rabbits. Am. J. Obstet. Gynec. 105, 529-534.

Received 19 September 1976 